Contribution to the development of DOE ARM Climate Best Estimate Data (ARMBE) products: Land Surface Forcing and Evaluation Data Set (ARMBE-LAND) from the ARM SGP site

M. Jin

June 19, 2013 
This document was prepared as an account of work sponsored by an agency of the United States government. Neither the United States government nor Lawrence Livermore National Security, LLC, nor any of their employees makes any warranty, expressed or implied, or assumes any legal liability or responsibility for the accuracy, completeness, or usefulness of any information, apparatus, product, or process disclosed, or represents that its use would not infringe privately owned rights. Reference herein to any specific commercial product, process, or service by trade name, trademark, manufacturer, or otherwise does not necessarily constitute or imply its endorsement, recommendation, or favoring by the United States government or Lawrence Livermore National Security, LLC. The views and opinions of authors expressed herein do not necessarily state or reflect those of the United States government or Lawrence Livermore National Security, LLC, and shall not be used for advertising or product endorsement purposes.

This work performed under the auspices of the U.S. Department of Energy by Lawrence Livermore National Laboratory under Contract DE-AC52-07NA27344. 


\title{
Contribution to the development of DOE ARM Climate Best Estimate Data (ARMBE) products: Land Surface Forcing and Evaluation Data Set (ARMBE-LAND) from the ARM SGP site
}

\section{Final Report}

\author{
Principal Investigator: Dr. Menglin S. Jin \\ Dept. of Meteorology and Climate Science \\ San José State University \\ One Washington Square \\ San José, CA 95120 \\ Email: menglin.jin@sjsu.edu \\ Phone: 408-924-7371; Fax: 408-924-5191
}

Date: February 28, 2013

Period of performance: 02/2012 - 02/2013

Technical Officer: Dr. Shaocheng Xie

Atmospheric, Earth and Energy Division (L-103)

Lawrence Livermore National Laboratory

P.O. Box 808

Livermore, CA 94551

Email: xie2@llnl.gov

Phone: (925) 422-6023; Fax: (925) 422-7675 


\section{Review of the scope of work}

To support the LLNL ARM Best Estimate Data Products (ARMBE) data development, the San Jose State University (SJSU)'s group will provide the LLNL team yearly data files (in a format consistent with ARMBE) that contain variables from the instruments defined in Table 1 for the ARM SGP site during the available period. The ARMBE-Land data product will blend multiple ARM observations including the Energy Balance Bowen Ratio Station (EBBR), Soil Water and Temperature System (SWATs) and CO2 Flux (CO2FLX) data sets. The SJSU group will process these datasets with stringent quality controls to remove suspicious data points and average the quality controlled data over a desired temporal resolution (one hour). A qc-flag will be assigned to each variable to indicate how many valid data points are used to get the hourly mean data, consistent with other ARMBE fileds. Specific information about the ARMBE-Land dataset includes:

- $\quad$ Site: The ARM SGP Central Facility site (Lamont, OK).

- Period: available period of each dataset

- Temporal resolution: one hour

- Frequency of final ARMBE-LAND data files: Yearly

- Format of final ARMBE-LAND data files: netCDF

In addition to the above tasks, the SJSU group needs to generate the daily plots which contain original data and the ARMBE-LAND hourly data, as well as performs necessary checks (e.g., surface energy budget check and other consistency checks) to ensure the quality of the produced ARMBE-Land dataset for the science community. 
Table 1 contains the variables that need to be done in Phase I and the data sources

\begin{tabular}{|c|c|c|c|c|}
\hline Variables & Descriptions & Instruments & Datastreams & Periods \\
\hline \multirow[t]{2}{*}{ T_Soil } & \multirow[t]{2}{*}{ soil temperature } & CO2FLX & sgp30co2flx4mmetC1.b1 & $12 / 2002-2012$ \\
\hline & & EBBR & sgp30ebbrE13.b1 & 7/1992-2012 \\
\hline \multirow[t]{2}{*}{ q_Soil } & \multirow[t]{2}{*}{ Soil moisture } & CO2FLX & sgp30co2flx4mmetC1.b1 & $12 / 2002-2012$ \\
\hline & & EBBR & sgp30ebbrE13.b1 & 7/1992-2012 \\
\hline \multirow[t]{2}{*}{ H_Soil } & \multirow[t]{2}{*}{ Soil heat flux } & CO2FLX & sgp30co2flx4mmetC1.b1 & $12 / 2002-201$ \\
\hline & & EBBR & sgp30ebbrE13.b1 & $7 / 1992-2012$ \\
\hline T_soil_prof & $\begin{array}{l}\text { Soil temperature } \\
\text { profile }\end{array}$ & SWATS & sgpswatsE13.b1 & $2 / 1996-2012$ \\
\hline q_soil_prof & $\begin{array}{l}\text { Soil moisture } \\
\text { profile }\end{array}$ & SWATS & sgpswatsE13.b1 & 2/1996-2012 \\
\hline fc_corr & $\begin{array}{l}\text { WPL corrected } \\
\text { CO2 flux }\end{array}$ & CO2FLX & sgp30co2flx4mmetC1.b1 & $12 / 2002-2012$ \\
\hline Ustar & friction velocity & CO2FLX & sgp30co2flx4mmetC1.b1 & $12 / 2002-2012$ \\
\hline $\begin{array}{l}\text { CO2 (@4m } \\
\& 25 \mathrm{~m})\end{array}$ & $\begin{array}{l}\text { Mean CO2 } \\
\text { density }\end{array}$ & CO2FLX & sgp30co2flx4mmetC1.b1 & $12 / 2002-2012$ \\
\hline ppfd & $\begin{array}{l}\text { photosynthetic } \\
\text { photon flux } \\
\text { density (PAR) }\end{array}$ & CO2FLX & sgp30co2flx4mmetC1.b1 & $12 / 2002-2012$ \\
\hline ppfd_up & $\begin{array}{l}\text { Upwelling } \\
\text { photosynthetic } \\
\text { photon flux } \\
\text { density (PAR) }\end{array}$ & CO2FLX & sgp30co2flx4mmetC1.b1 & $12 / 2002-2012$ \\
\hline
\end{tabular}




\section{Technical Details}

\subsection{Inconsistency in data filenames and missing data files}

There are cases that ARM data filename changes over the data collection periods or missing data files for certain periods. This has caused difficulties in automatically processing data over multiple years. Approaches to handle such conditions have been developed during the data development.

\subsection{Some issues with SWATS data}

SWATS data are available at 8 layers, however, data at the deepest two layers are missing. So the final data product only includes data at the first 6 layers $(5 \mathrm{~cm}, 15 \mathrm{~cm}, 25 \mathrm{~cm}, 35 \mathrm{~cm}, 60 \mathrm{~cm}, 85 \mathrm{~cm})$.

\subsection{Quality Checks}

The qc flags in each data file are used to remove the bad data, the data is set to be -9999.0 if the qc flag is not equal to 0 . At the same time, the maximum and minimum check and the outlier check according to standard deviations are also used to remove the bad data and set them into -9999.0

\subsection{Hourly average}

\subsubsection{CO2FLX data}

The original data is half-hourly averaged data, and the data is reported at the beginning of each half-hour, the timestamp "time_offset" stands for the time offset from the "basetime”, basetime sets at 00:00:00 GMT. The first number 0 in time_offset stands for the data which are averaged for the first half hour (00:00 UTC 00:30 UTC) of the day, the second number 1800 stands for the average of the second half hour (00:30UTC 01:00UTC) of the day. So for the ARMBE-LAND, the first 2 original data are averaged and report at 00:30UTC as the first data. And so on.

$$
\begin{aligned}
& \text { time_offset }=0,1800,3600,5400,7200,9000,10800,12600,14400,16200, \\
& \text { 18000, 19800, 21600, 23400, 25200, 27000, 28800, 30600, 32400, 34200, } \\
& \text { 36000, 37800, 39600, 41400, 43200, 45000, 46800, 48600, 50400, 52200, } \\
& \text { 54000, 55800, 57600, 59400, 61200, 63000, 64800, 66600, 68400, 70200, } \\
& \text { 72000, 73800, 75600, 77400, 79200, 81000, 82800, 84600 }
\end{aligned}
$$

\subsubsection{SWATS data:}

For swats original data, the instruments take data once an hour and always start on the hour and take approximately 7 minutes to complete the procedure, which is why the time starts at 420 seconds. The base_time is set at 0:07:00 GMT, so each data is reported at 00:07 UTC. Nothing is done for SWATS data except for suspicious data removal using the quality checks defined above.

time_offset $=0,3600,7200,10800,14400,18000,21600,25200,28800$,

32400, 36000, 39600, 43200, 46800, 50400, 54000, 57600, 61200, 64800,

68400, 72000, 75600, 79200, 82800 ; 
time $=420,4020,7620,11220,14820,18420,22020,25620,29220,32820$, 36420, 40020, 43620, 47220, 50820, 54420, 58020, 61620, 65220, 68820,

72420, 76020, 79620, 83220 ;

\subsubsection{EBBR data}

The original data is half-hour average data and the basetime is set at 23:30:00 GMT. The time is assigned to the end of the averaging interval, so the first data stands for the 23:30-00:00. For the ARMBE-LAND data, we should average the second and third original data then report at 00:30UTC as the first data.

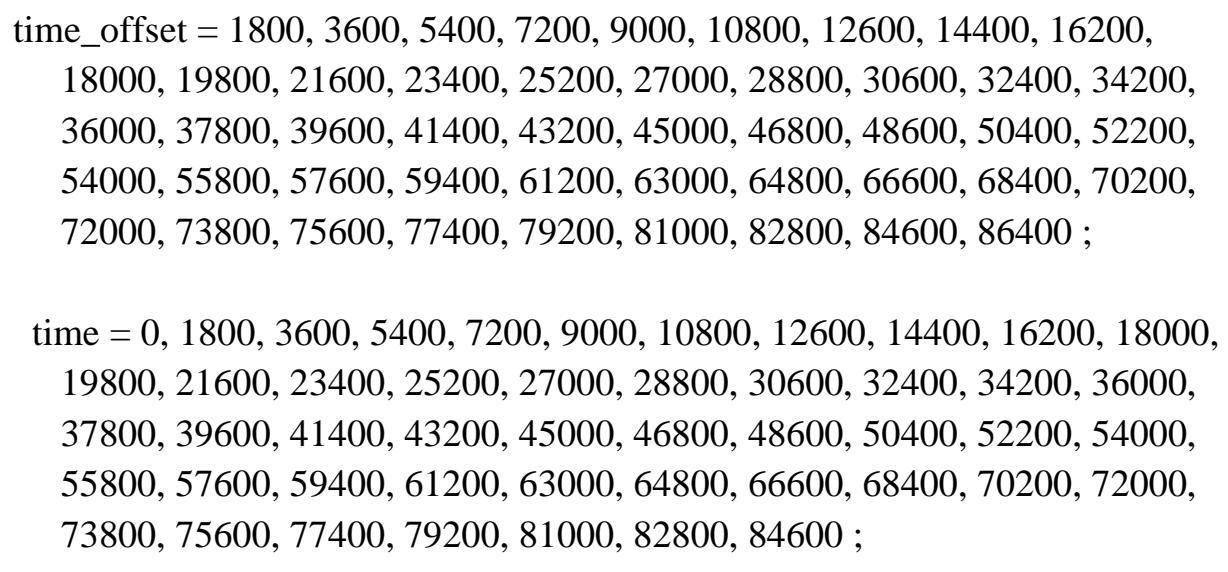

\subsection{Daily plots}

Each plot contains the original data and the ARMBE-LAND data as shown in Figures 1-3.

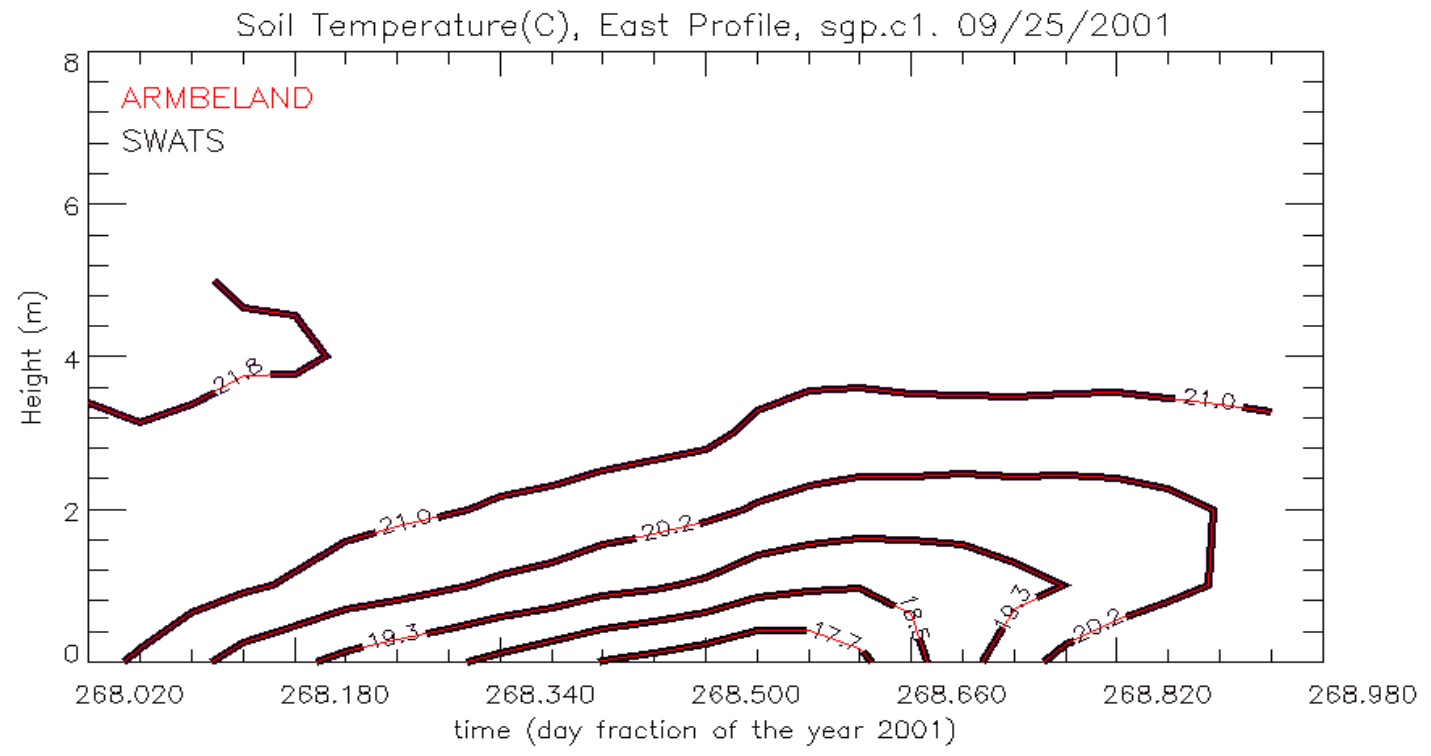

Figure 1. soil temperature (units: C) of the east profile on sep. 25, 2001 of swats data. 


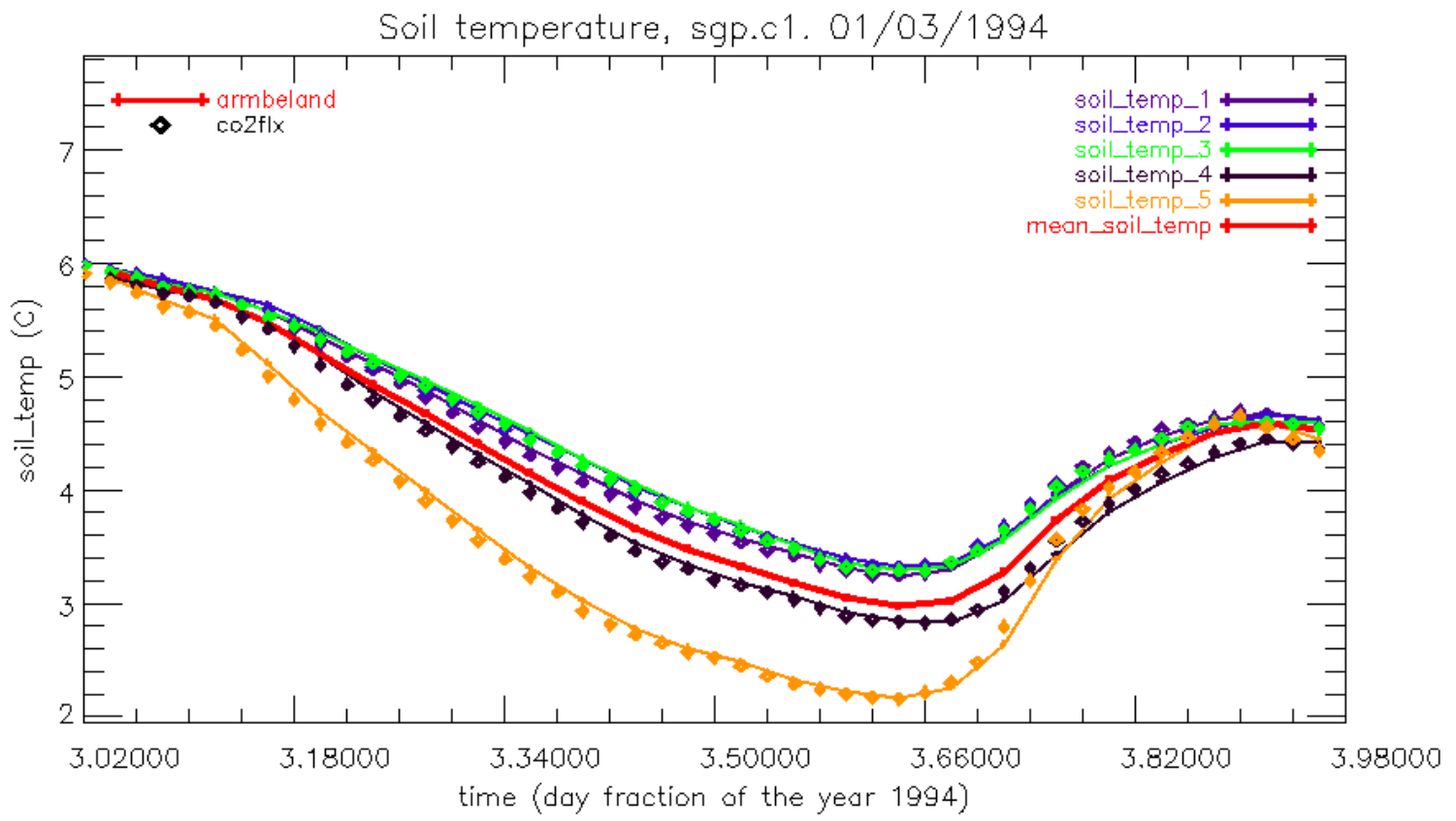

Figure 2. soil temperature (units: C) on Jan. 3, 1994 of EBBR data.

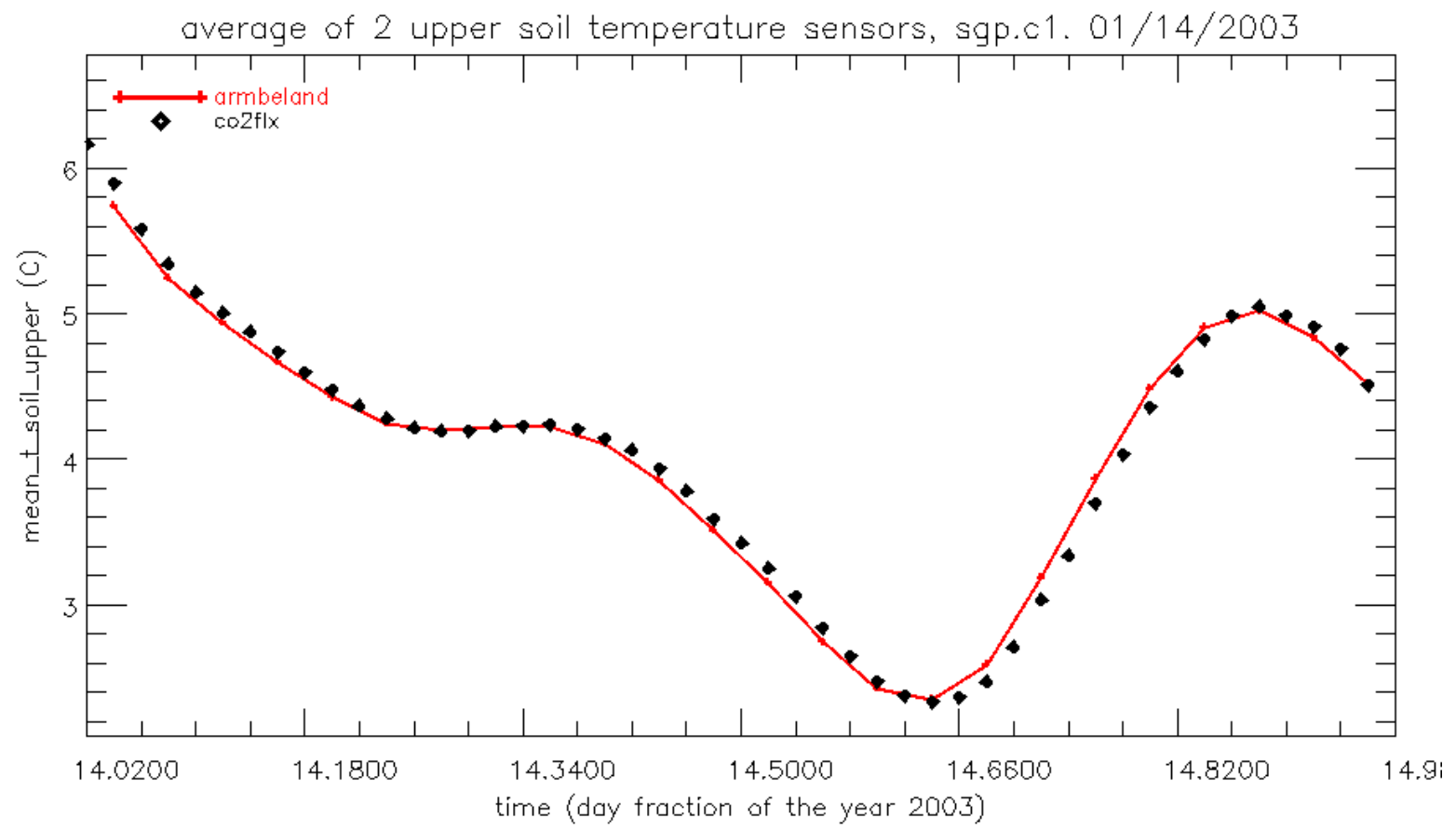

Figure 3. Average of two upper soil temperature sensors (units: C) on Jan. 14, 2003 of co2flx data. 


\section{Summary}

In summary, we have successfully completed this one-year subcontract with the LLNL ARM infrastructure team and delivered all the required data products to LLNL in support of the development of the ARMBE-LAND data. The original data period and the ARMBE-LAND data period are list below.

- Original data

- co2flxdata: 1/1/2003 - 12/31/2012

- swatsdata: 2/5/1996-12/31/2012

- ebbrdata: 9/1/1993-12/31/2012

$$
\begin{aligned}
& \text { ARMBE-LAND data } \\
& 1 / 1 / 2003-12 / 31 / 2012 \\
& 1 / 1 / 1996-12 / 31 / 2012 \\
& 1 / 1 / 1994-12 / 31 / 2012
\end{aligned}
$$

\section{Reference}

Jin, M. H. Bartholomew, T. Mullens, R. E. Dickinson, 2011: Evaluate Offline CLM4

Skin Temperature Simulation Using ARM Oklahoma Observations. NCAR CESM workshop, June 20-23, Breckridge, CO.

Jin, M. and R. E. Dickinson, 1999: Interpolation of surface radiation temperature measured from polar orbiting satellites to a diurnal cycle. Part 1: Without Clouds. Journal of Geophysical Research, 104, 2105-2116.

Jin, M. and R. E. Dickinson 2000: A Generalized algorithm for retrieving cloudy sky skin temperature from satellite thermal infrared radiances. Journal of Geophysical Research, D22, 27,037-27,047.

Xie, S., R.B. McCoy, S.A. Klein, R.T. Cederwall, W.J. Wiscombe, E.E. Clothiaux, K.L. Gaustad, J.C. Golaz, S.D. Hall, M.P. Jensen, K.L. Johnson, Y. Lin, C.N. Long, J.H. Mather, R.A. McCord, S.A. McFarlane, G. Palanisamy, Y. Shi, and D.D. Turner, 2010: CLOUDS AND MORE: ARM Climate Modeling Best Estimate Data. Bull. Amer. Meteor. Soc., 91, 13-20. DOI: 10.1175/2009BAMS2891.

Acknowledgments. This work is supported by the Atmospheric Radiation Measurement Program of the Office of Science at the U.S. Department of Energy. Work at LLNL was performed under the auspices of theU.S.Department of Energy, Office of Science, Office of Biological and Environmental Research by Lawrence Livermore National Laboratory under Contract DE-AC52-07NA27344. 